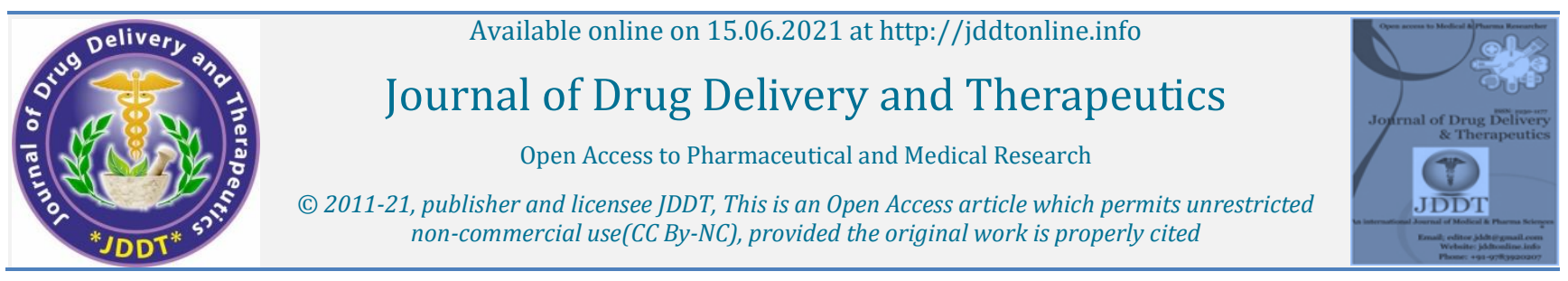

Open Access Full Text Article

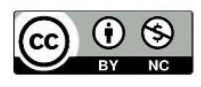

Short Communication

\title{
Formulation and In-Vitro Evaluation of Orally Disintegrating Tablets (ODTs) of Tramadol Hydrochloride
}

\author{
(D) Jesmin Akter ${ }^{1}$, (D) Nusrat Ahmed ${ }^{2 *}$, (D)Sabrina Rahman Archie ${ }^{2}$ \\ ${ }^{1}$ Department of Pharmacy, University of Dhaka, Dhaka-1000, Bangladesh \\ 2 Department of Pharmaceutical Technology, Faculty of Pharmacy, University of Dhaka, Dhaka-1000, Bangladesh
}

\begin{tabular}{ll}
\hline Article Info: & \\
\hline article History: \\
\hline
\end{tabular}

\section{Cite this article as:}

Akter J, Ahmed N, Archie SR, Formulation and In-Vitro Evaluation of Orally Disintegrating Tablets (ODTs) of Tramadol Hydrochloride, Journal of Drug Delivery and Therapeutics. 2021; 11(3-S):1-6

DOI: http://dx.doi.org/10.22270/jddt.v11i3-S.4875

\author{
Abstract
}

\begin{abstract}
Since orally disintegrating tablets (ODTs) of tramadol hydrochloride are not available in the market, so an attempt has been taken to formulate and evaluate ODT preparation of tramadol hydrochloride. In this present work, direct compression was the technique used for preparing ODT using superdisintegrants like croscarmellose sodium, sodium starch glycolate and crospovidone at different concentrations. Prepared formulations were evaluated for various quality parameters- angle of repose, Carr's index, Hausner ratio, weight variation, friability, hardness, drug content, dispersion time, wetting time and invitro dissolution. The angle of repose data indicated that the flow property of all the formulations was good to excellent. Comparing with the specifications, the results of Carr's index (\%) and Hausner's ratio indicated that the flowability of all the formulations blend was significantly good. Prepared formulations showed average wetting time ranging from 40-45 seconds, average dispersion time with 3-6 minutes. In-vitro dissolution profile indicated the cumulative $\%$ drug release between $30-80 \%$ for most of the cases.
\end{abstract}

Keywords: Orally disintegrating tablets, Tramadol hydrochloride, Superdisintegrants, Direct compression.

\section{*Address for Correspondence:}

Nusrat Ahmed, Department of Pharmaceutical Technology, Faculty of Pharmacy, University of Dhaka, Dhaka-1000, Bangladesh.

ORCID ID: https://orcid.org/0000-0002-6059-0247

\section{INTRODUCTION}

Many patients like pediatric and geriatric, disabled, bedridden or uncooperative, face difficulties while taking traditional dosage forms like tablets due to swallowing problem. Orally disintegrating tablets (ODTs) can be a better alternative for these kind of patients, as they are more convenient and patient compliant. Orally disintegrating tablet rapidly disintegrates and dissolves in saliva when placed upon tongue and does not require additional water for swallowing. ${ }^{1,2}$

United States Food and Drug Administration (FDA) defined ODT as "A solid dosage form containing medicinal substance or active ingredient which disintegrates rapidly usually within a matter of seconds when placed upon the tongue". European Pharmacopeia used the term orodispersible tablets and defined as a tablet that when placed in the mouth disperses within 3 minutes before swallowing. 3,4

The aim of this study was to formulate ODTs to achieve rapid disintegration in the mouth without water. Study was designed by using different superdisintegratescroscarmellose sodium, sodium starch glycolate and crospovidone at different concentrations to evaluate their effect on various quality parameters. Tramadol hydrochloride was selected as the model drug in the study.

Tramadol is a centrally acting, synthetic opioid analgesic, which is used to treat moderate to severe pain like postoperative pain, traumatic pain and cancer pain. It is rapidly absorbed after oral administration with mean bioavailability of approximately $75 \%$. Its onset of action is occurred within 30-60 minutes and elimination half-life is about 6 hours. $1,5,6$

The capsule dosage form and sustained release tablet of tramadol hydrochloride are available in Bangladesh for oral administration. There is no marketed ODT preparation in Bangladesh, but in USA and Europe tramadol hydrochloride ODT preparations are currently available. Thus, in this work an attempt has been taken to formulate and evaluate orally disintegrating tablets of tramadol hydrochloride.

\section{MATERIALS AND METHODS}

\section{Materials:}

Tramadol hydrochloride API (Active Pharmaceutical Ingredient) was obtained from Beximco Pharmaceuticals Ltd. as a gift sample. Other excipients were obtained from Pharmaceutical Technology Lab, University of Dhaka. Nine 
formulations were prepared, among them three formulations coded as formulation A (A1, A2, A3) in which croscarmellose sodium, formulation B (B1, B2, B3) in which sodium starch glycolate and formulation C (C1, C2, C3) in which crospovidone was used as superdisintegrant at different concentrations.

Table 1: Ingredients used in tramadol hydrochloride ODT formulation.

\begin{tabular}{ll}
\hline Ingredients & Justification \\
\hline Tramadol hydrochloride & API \\
Croscarmellose & Superdisintegrant \\
Sodium starch glycolate & Superdisintegrant \\
Crospovidone & Superdisintegrant \\
Microcrystalline cellulose (Avicel) & Diluent \\
Sodium saccharine & Sweeting agent \\
Magnesium stearate & Lubricant \\
Aerosil & Flow promoter \\
Mannitol & Taste masking agent \\
Pregelatinized starch & Binder \\
\hline
\end{tabular}

\section{Formulation by direct compression method:}

Total nine formulations (Table 2) of tramadol hydrochloride ODT were prepared by direct compression method.
Required amount of ingredients were weighed and mixed in mortar and pestle. Then the blend was passed through a 40 number mesh size aperture and collected. Finally the mixture was compressed using Rotary Punch Machine.

Table 2: Formulation of tramadol hydrochloride ODTs (All Amounts taken in mg).

\begin{tabular}{llllllllll}
\hline Formulation/ Ingredients & A1 & A2 & A3 & B1 & B2 & B3 & C1 & C2 & C3 \\
\hline $\begin{array}{l}\text { Tramadol } \\
\text { Hydrochloride }\end{array}$ & 50 & 50 & 50 & 50 & 50 & 50 & 50 & 50 & 50 \\
$\begin{array}{l}\text { Croscarmellose } \\
\text { Sodium }\end{array}$ & 12.5 & 2.5 & 5 & - & - & - & - & - & - \\
Sodium starch & & & & & & & & \\
Glycolate & - & - & - & 5 & 10 & 7.5 & - & - & - \\
Crospovidone & & & & & & & & & \\
Microcrystalline cellulose & 125 & 150 & 112 & 125 & 150 & 137 & 125 & 137 & 150 \\
Sodium saccharine & 5 & 2.5 & 3.75 & 5 & 3.75 & 2.5 & 3.75 & 2.5 & 5 \\
Magnesium stearate & 2.5 & 0.625 & 1.25 & 7.5 & 5 & 2.5 & 12.5 & 5 & 7.5 \\
Aerosil & 1.25 & 2.5 & 1.88 & 1.25 & 2.5 & 0.63 & 2.5 & 0.63 & 1.25 \\
Mannitol & 43.8 & 16.88 & 38.1 & 43.75 & 18.8 & 41.9 & 38.8 & 36.9 & 21.25 \\
Pregelatinized starch & 10 & 25 & 37.5 & 12.5 & 10 & 7.5 & 12.5 & 5 & 7.5 \\
Total & 250 & 250 & 250 & 250 & 250 & 250 & 250 & 250 & 250 \\
\hline
\end{tabular}

\section{Pre-compression parameters:}

The powder mixture was characterized for angle of repose, bulk density, tapped density, Carr's index and Hausner's ratio.

\section{Angle of repose ( $\theta)$ :}

The highest or the maximum angle possible between the surface of a pile of powder or granules and the horizontal plane is called angle of repose.

$$
\begin{gathered}
\tan \theta=h / r \\
\theta=\tan ^{-1}(h / r)
\end{gathered}
$$

Where, $\theta$ is the angle of repose, $h$ is the height of powder heap, $r$ is the radius of the base of powder heap.

A cup was taken and its radius was measured from the diameter of it. A funnel was set above a cup using stand and clamp at definite height, adjusted in such a way that its tip just touched the apex of the heap of the powder. The mixture was allowed to flow freely through the funnel onto the cup surface. The height of the heap apex from the floor was measured and height of the cup was subtracted from it to obtain the height of the heap. 7,8

\section{Carr's index and Hausner ratio:}

Accurately weighted amount of blend (1gm) was taken in a measuring cylinder. The initial volume was measured and then the cylinder was tapped for 100 times on a plane hard wooden surface. LBD (Loose bulk density) and TBD (Tapped bulk density) were then calculated using following equations: ${ }^{9}$

$$
\begin{aligned}
& \text { Weight of the blend } \\
& \mathrm{LBD}= \\
& \text { Initial Volume of the packing } \\
& \text { Weight of the blend } \\
& \mathrm{TBD}=
\end{aligned}
$$

Carr's index and Hausner's ratio were determined using respective equations shown below: 


$$
\begin{gathered}
\text { Carr's index }(\%)=\frac{\text { TBD }-\mathrm{LBD}}{\mathrm{TBD}} \times 100 \\
\text { Hausner's ratio }=\frac{\mathrm{TBD}}{\mathrm{LBD}}
\end{gathered}
$$

\section{Friability test:}

Three tablets from each batch were taken randomly and weighed. The tablets were then placed into the friabilator and run at $25 \mathrm{rpm}$ for 4 min (totally 100 revolutions). Then the tablets were taken out and reweighed. 10,11 Friability (\%) was then calculated by the following equation:

$$
\% \text { Friability }=\frac{\text { Initial weight }- \text { Final weight }}{\text { Initial weight }} \times 100
$$

The percentage friability value must be less than or equal to $1 \%$ to meet the specification. ${ }^{10}$

\section{Weight variation test:}

Ten tablets were taken randomly from each batch and weighed individually. The average weight was then calculated. The percentage difference was calculated using the following formula-

$$
\text { Weight variation }(\%)=\left[\left(\mathrm{I}_{\mathrm{w}}-\mathrm{A}_{\mathrm{w}}\right) / \mathrm{A}_{\mathrm{w}}\right] \times 100
$$

Where, $I_{w}=$ Individual weight of each tablet, $A_{w}=$ Average weight of tablet

The percentage difference in the weight variation should be within the acceptable limits $( \pm 7.5 \%$ for tablet weight of more than $80 \mathrm{mg}$ but less than $250 \mathrm{mg}$ ). 12,13

\section{Hardness test:}

Three prepared tablets of each batch were taken and placed vertically in a digital hardness tester. ${ }^{11}$ Then the machine was pressed to check the hardness of the tablet at which point the tablet crushes. The force required to break tablet was measured in kilograms and a crushing strength of 2-3 $\mathrm{kg} / \mathrm{cm}^{2}$ is usually acceptable.

\section{Diameter and thickness test:}

The diameter and thickness of three tablets from each of the batches were measured by using digital slide calipers. Then average diameter and thickness were calculated.

\section{Wetting time test:}

$6 \mathrm{ml}$ purified water was poured into a petri dish which internal diameter was $5.7 \mathrm{~cm}$. A piece of tissue paper folded twice was placed over that petri dish. From each batch of prepared tablets, one tablet was taken and kept on the tissue paper and allowed to wet completely. The time needed for complete wetting of the tablet was then noted down. ${ }^{11,14}$

\section{Dispersion time test:}

A petri dish $(5.7 \mathrm{~cm}$ internal diameter) was filled with $9 \mathrm{ml}$ of phosphate buffer solution simulating saliva $\mathrm{pH}$ 6.8. One tablet was taken from each batch and was carefully placed in the center of petri dish. Then time required for the tablet to completely disintegrate into fine particles was reported. ${ }^{13}$

\section{Dissolution test:}

Dissolution study was performed using USP type-II apparatus with $900 \mathrm{ml}$ of phosphate buffer (pH 6.8) as the dissolution medium. The apparatus was set at $25 \mathrm{rpm}$ for 40 minutes. From each batch, three tablets were taken for dissolution test. Five $\mathrm{ml}$ of aliquots were withdrawn at regular time intervals and the medium volume was maintained by adding an equal volume of fresh dissolution medium. Withdrawn solution was filtered. Then $0.2 \mathrm{ml}$ filtrate was taken and adjusted to $10 \mathrm{ml}$ with prepared phosphate buffer pH 6.8 (50 times dilution). The collected samples were analyzed spectrophotometrically at $271 \mathrm{~nm}$. 13,15

\section{Drug content test:}

From each batch one tablet was taken randomly and crushed in a mortar. The powdered sample equivalent to $10 \mathrm{mg}$ of tramadol hydrochloride was weighed, and dissolved in suitable volume of phosphate buffer $(\mathrm{pH}$ 6.8). The final volume was adjusted to $100 \mathrm{ml}$ and the drug content was analyzed using UV spectrophotometer at $271 \mathrm{~nm} .{ }^{1,12}$

\section{RESULTS AND DISCUSSION}

\section{Pre-compression properties:}

Pre-compression parameters of powder blend i.e., angle of repose, Carr's index and Hausner's ratio were calculated as shown in Table 3. The angle of repose data indicated that the flow property of all the formulations was in the range of good to excellent. Comparing with the specifications, the results of Carr's index (\%) and Hausner's ratio indicated that the flowability of the entire formulations blend was significantly good.

Table 3: Evaluation of pre-compression properties of powder blend.

\begin{tabular}{llll}
\hline Formulation & Angle of repose $\left({ }^{0}\right)$ & Carr's index (\%) & Hausner's ratio \\
\hline A1 & 20.2 & 11.92 & 1.73 \\
A2 & 18.39 & 17.8 & 1.5 \\
A3 & 35.7 & 11.8 & 1.99 \\
B1 & 29.25 & 9.6 & 1.1 \\
B2 & 29.6 & 14.98 & 1.96 \\
B3 & 26.9 & 19.51 & 1.23 \\
C1 & 30.7 & 12.01 & 1.49 \\
C2 & 35.75 & 7.9 & 1.18 \\
C3 & 24.8 & 13.89 & 1.16 \\
\hline
\end{tabular}


Table 4: Specification for angle of repose.

\begin{tabular}{ll}
\hline Angle of repose $\left({ }^{0}\right)$ & Flow character \\
\hline $25-30$ & Excellent \\
$31-35$ & Good \\
$36-40$ & Fair - aid not needed \\
$41-45$ & Passable - may hang up \\
$46-55$ & Poor - must agitate, vibrate \\
$56-65$ & Very poor \\
$>66$ & Very, very poor \\
\hline
\end{tabular}

Table 5: Specification for Carr's index and Hausner's ratio.

\begin{tabular}{lll}
\hline Carr's index (\%) & Flow character & Hausner's ratio \\
\hline$<10$ & Excellent & $1.00-1.11$ \\
$11-15$ & Good & $1.12-1.18$ \\
$16-20$ & Fair & $1.19-1.25$ \\
$21-25$ & Passable & $1.26-1.34$ \\
$26-31$ & Poor & $1.35-1.45$ \\
$32-37$ & Very poor & $1.46-1.59$ \\
$>38$ & Very, very poor & $>1.60$ \\
\hline
\end{tabular}

\section{Evaluation of physicochemical properties:}

Less deviation in tableting physical parameters like weight variation, diameter and thickness indicates the batch uniformity. To withstand mechanical shocks during handling, packaging and shipping adequate hardness and resistance to friability of tablet are required. Hardness and friability of a tablet have direct impact on the disintegration and dissolution process. ${ }^{16}$ All these parameters of the prepared formulations meet the specifications previously mentioned in the materials and methods part. The results are given in table 6. All the prepared tablets maintained hardness between $2.48-3.56 \mathrm{~kg} / \mathrm{cm}^{2}$. \% friability was less than $1 \%$ which meets the criteria.

The wetting time of all the formulations was within acceptable limit for ODT preparation. Among all the formulations, batch $\mathrm{C} 1$ had lowest wetting time of 35 seconds. In case of dispersion time, batch A1 showed the minimum (3.3 min) dispersion time.

Table 6: Physicochemical parameters of prepared formulations.

\begin{tabular}{llllllll}
\hline Formulation & Friability (\%) & $\begin{array}{l}\text { Weight } \\
\text { variation }\end{array}$ & $\begin{array}{l}\text { Hardness } \\
\left(\mathrm{kg} / \mathrm{cm}^{2}\right)\end{array}$ & $\begin{array}{l}\text { Diameter } \\
(\mathrm{mm})\end{array}$ & $\begin{array}{l}\text { Thickness } \\
(\mathrm{mm})\end{array}$ & $\begin{array}{l}\text { Wetting } \\
\text { time } \\
(\mathrm{sec})\end{array}$ & $\begin{array}{l}\text { Dispersion } \\
\text { time } \\
(\mathrm{min})\end{array}$ \\
\hline A1 & 0.263 & Pass & 3.47 & 9.13 & 4.06 & 40 & 3.3 \\
$\mathrm{~A} 2$ & 0.266 & Pass & 3.17 & 9.13 & 3.98 & 39 & 3.4 \\
A3 & 0.265 & Pass & 3.56 & 9.14 & 4.07 & 48 & 4 \\
B1 & 0.534 & Pass & 2.48 & 9.15 & 3.92 & 38 & 5.3 \\
B2 & 0.4 & Pass & 3 & 9.08 & 3.97 & 41 & 6.5 \\
B3 & 0.265 & Pass & 3.14 & 9.14 & 3.97 & 51 & 5.25 \\
C1 & 0.405 & Pass & 2.49 & 9.12 & 4.07 & 35 & 7 \\
C2 & 0.535 & Pass & 3.06 & 9.10 & 4.03 & 39 & 6.01 \\
C3 & 0.4 & Pass & 3.01 & 9.11 & 4.13 & 45 & 5.09 \\
\hline
\end{tabular}




\section{Dissolution test:}

In vitro drug release profile of prepared ODTs is shown in Table 7. The tablets prepared from crospovidone (C1- C3) showed a drug release between 76.86- $92.33 \%$ in 40 minutes and that of croscarmellose sodium showed a drug release of more than $90 \%$. Cumulative \% drug release was between $30-80 \%$ for most of the cases. Thus, croscarmellose sodium at $1 \%, 2 \%$ and $5 \%$ concentrations (range $0.5-5 \%$ $\mathrm{w} / \mathrm{w})$, sodium starch glycolate at $2 \%, 3 \%$ and $4 \%$ concentrations (range $2-8 \% \mathrm{w} / \mathrm{w}$ ) and crospovidone at $2 \%$, $3 \%$ and $5 \%$ (range $2-5 \% \mathrm{w} / \mathrm{w}$ ) concentrations can be used for ODT formulation of tramadol hydrochloride for better release.

Table 7: Cumulative \% drug release of prepared formulations.

\begin{tabular}{llllllllll}
\hline \multicolumn{10}{c}{ Cumulative \% drug release } \\
\hline Time (min) & A1 & A2 & A3 & B1 & B2 & B3 & C1 & C2 & C3 \\
5 & 30.00 & 40.00 & 35.00 & 20.06 & 40.03 & 50.10 & 33.33 & 30.50 & 34.07 \\
10 & 35.14 & 45.22 & 45.19 & 30.00 & 45.22 & 59.28 & 35.17 & 39.17 & 40.22 \\
15 & 50.36 & 50.47 & 55.44 & 35.16 & 55.47 & 65.56 & 45.36 & 50.33 & 50.44 \\
30 & 81.36 & 76.44 & 81.50 & 55.81 & 76.50 & 76.69 & 61.17 & 71.28 & 81.44 \\
40 & 97.25 & 92.30 & 97.42 & 81.47 & 92.36 & 92.61 & 76.86 & 87.06 & 92.33 \\
\hline
\end{tabular}

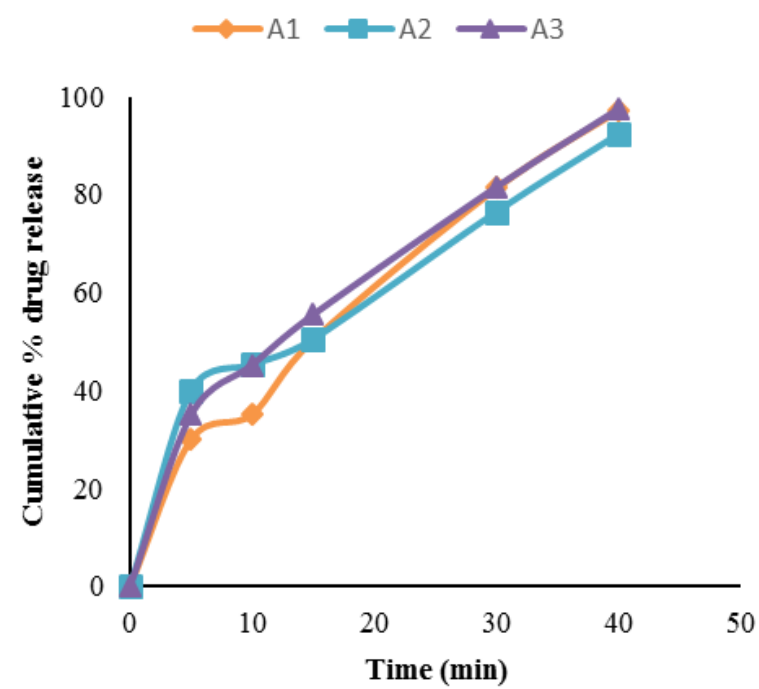

Figure 1: In- vitro drug release profile of batch A1-A3.

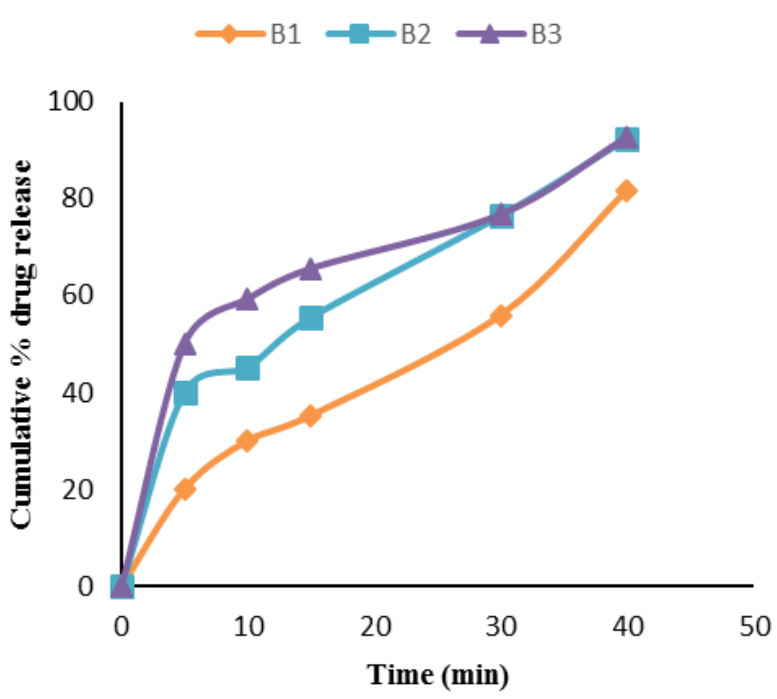

Figure 2: In- vitro drug release profile of batch B1-B3.

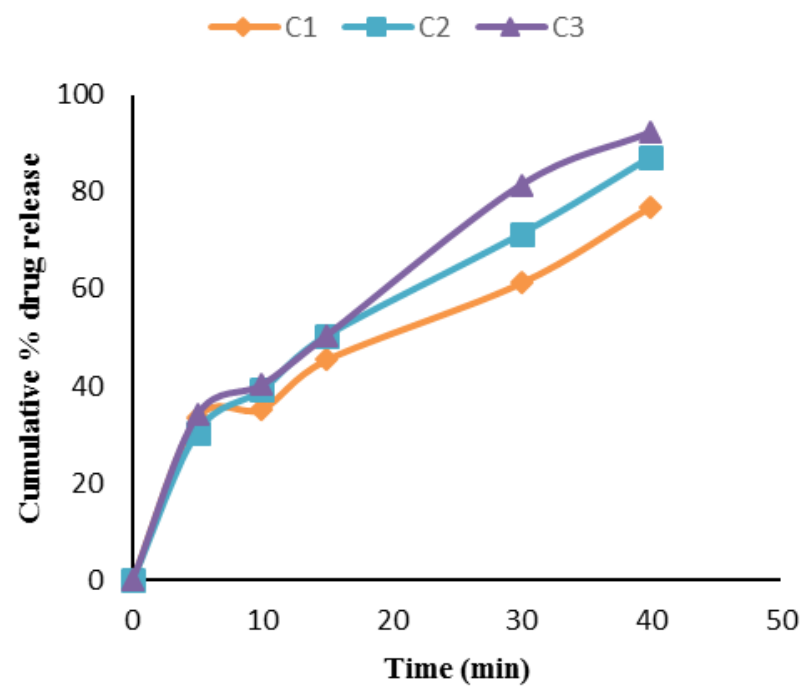

Figure 3: In- vitro drug release profile of batch C1-C3. 


\section{Drug content test:}

In the determination of drug content, batch A had maximum amount of drug (approximately 100\%) compared to others and each batch met the quality standard. The permitted official potency range is not less than $90 \%$ and not more than $110 \%$ for most low dose drugs,. 16 All of the formulations met this criteria.

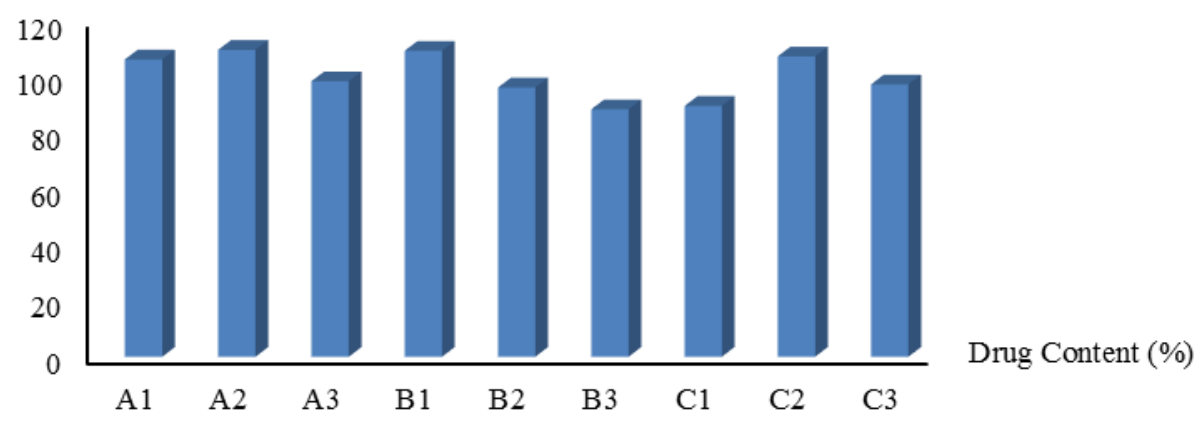

Figure 4: Drug content (\%) of prepared formulations.

\section{CONCLUSION}

The goal of this present project was to evaluate the quality parameters of tramadol hydrochloride ODTs of different formulations (A, B and C). From this study, it was revealed that three superdisintegrants- croscarmellose sodium, sodium starch glycolate and crospovidone at optimum concentrations can be used for tramadol hydrochloride ODT formulation. Overall it can be summarized that, this work showed a good result of quality parameters.

\section{ACKNOWLEDGEMENT}

The authors would like to thank Beximco Pharmaceuticals Ltd. for providing the necessary chemicals and supporting the work.

\section{CONFLICT OF INTEREST}

The author has no conflict of interest.

\section{REFERENCES}

1. Wajid S, Al-Arifi MN, Al Saleh SS, Babelgaith SD, Al Saleh SS, Mohamed AR, Design and evaluation of orally disintegrating tramadol hydrochloride tablets by direct compression method, British Journal of Pharmaceutical Research, 2015; 8(4):1-8. DOI: http://dx.doi.org/10.9734/BJPR/2015/19392

2. Roy A, Orodispersible tablets: A review, Asian Journal of Pharmaceutical and Clinical Research, 2016; 9(1):19-26.

3. Sharma V, Singh SP, Nama N, Khinchi MP, Formulation and evaluation of orally disintegrating tablet of lamotrigine, Asian Journal of Pharmaceutical Research and Development, 2017; 5(2):1-10.

4. Dey P, Maiti S, Orodispersible tablets: A new trend in drug delivery, Journal of Natural Science, Biology and Medicine, 2010; 1(1):2-5. DOI: https://dx.doi.org/10.4103\%2F0976-9668.71663

5. Patil MG, Kakade SM, Pathade SG, Formulation and evaluation of orally disintegrating tablet containing tramadol hydrochloride by mass extrusion technique, Journal of Applied Pharmaceutical Science, 2011; 1(6):178-181.

6. Patel KB, Shete SN, Belgamwar VS, Tekade AR, Formulation design and optimization of taste-masked mouth-dissolving tablets of tramadol hydrochloride, Asian Journal of Pharmaceutics, 2010; 4(3):239-245. DOI:
7. Shah RB, Tawakkul MA, Khan MA, Comparative evaluation of flow for pharmaceutical powders and granules, AAPS PharmSciTech. 2008; 9(1):250-258. DOI: https://doi.org/10.1208/s12249-008-9046-8

8. Remya KS, Beena P, Bijesh PV, Sheeba A, Formulation development, evaluation and comparative study of effects of super disintegrants in cefixime oral disintegrating tablets, Journal of Young Pharmacists, 2010; 2(3):234-239. DOI: https://dx.doi.org/10.4103\%2F0975-1483.66794

9. Pawar H, Varkhade C, Jadhav P, Mehra K, Development and evaluation of orodispersible tablets using a natural polysaccharide isolated from Cassia tora seeds, Integrative Medicine Research, 2014; 3(2):91-98. https://doi.org/10.1016/j.imr.2014.03.002

10. Türkmen O, Şenyiğit ZA, Baloğlu E, Formulation and evaluation of fexofenadine hydrochloride orally disintegrating tablets for pediatric use, Journal of Drug Delivery Science and Technology, 2018; 43:201-210. http://doi.org/10.1016/j.jddst.2017.10.008

DOI:

11. Ibrahim MA, Sayeh AE, Ela AE, Optimized furosemide taste masked orally disintegrating tablets, Saudi Pharmaceutical Journal, 2017; 25(7):1055-1062. https://dx.doi.org/10.1016\%2Fj.jsps.2017.04.002

12. Dave V, Yadav RB, Ahuja R, Yadav S, Formulation design and optimization of novel fast dissolving tablet of chlorpheniramine maleate by using lyophilization techniques, Bulletin of Faculty of Pharmacy, Cairo University, 55(1):31-39. https://doi.org/10.1016/J.BFOPCU.2016.12.001

13. Shah SJ, Mazumder R, Formulation development and evaluation of mouth dissolving tablet of tramadol hydrochloride, Asian Journal of Pharmaceutical and Clinical Research, 2013; 6(7):3136.

14. Puttewar TY, Kshirsagar MD, Chandewar AV, Chikhale RV, Formulation and evaluation of orodispersible tablet of taste masked doxylamine succinate using ion exchange resin, Journal of King Saud University-Science, 2010; 22(4):229-240. DOI: https://doi.org/10.1016/j.jksus.2010.05.003

15. Ponugoti RSR, Gonugunta CR, Formulation and evaluation of mouth dissolving tablets of tramadol hydrochloride. Tropical Journal of Pharmaceutical Research, 2014; 13(5):669-675. DOI: http://dx.doi.org/10.4314/tjpr.v13i5.3

16. Lachman L, Lieberman HA, Kanig JL. The theory and practice of industrial pharmacy. 3rd ed. Mumbai: Varghese Publishing House; 1987. P. 308. 